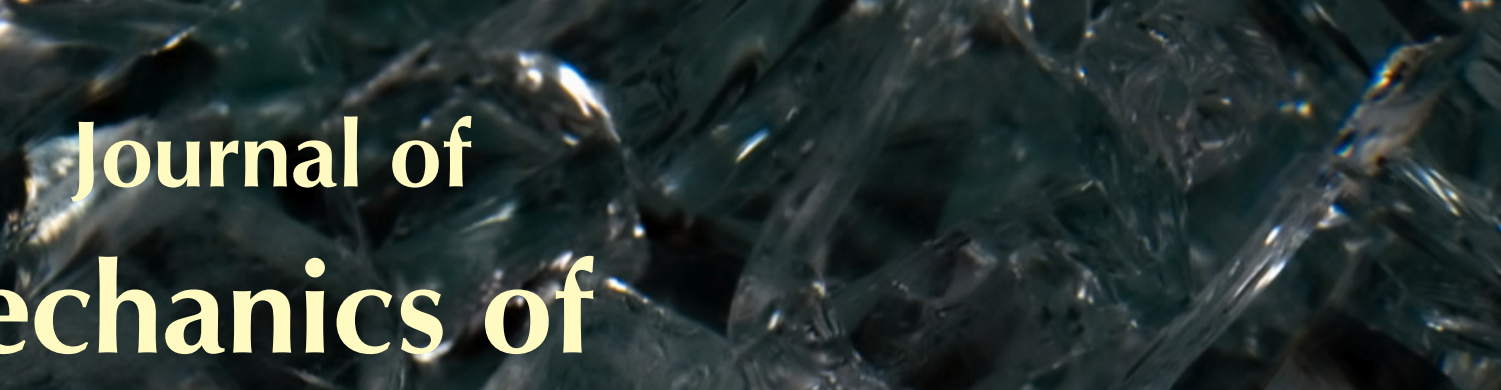

Materials and Structures

Mechanics of
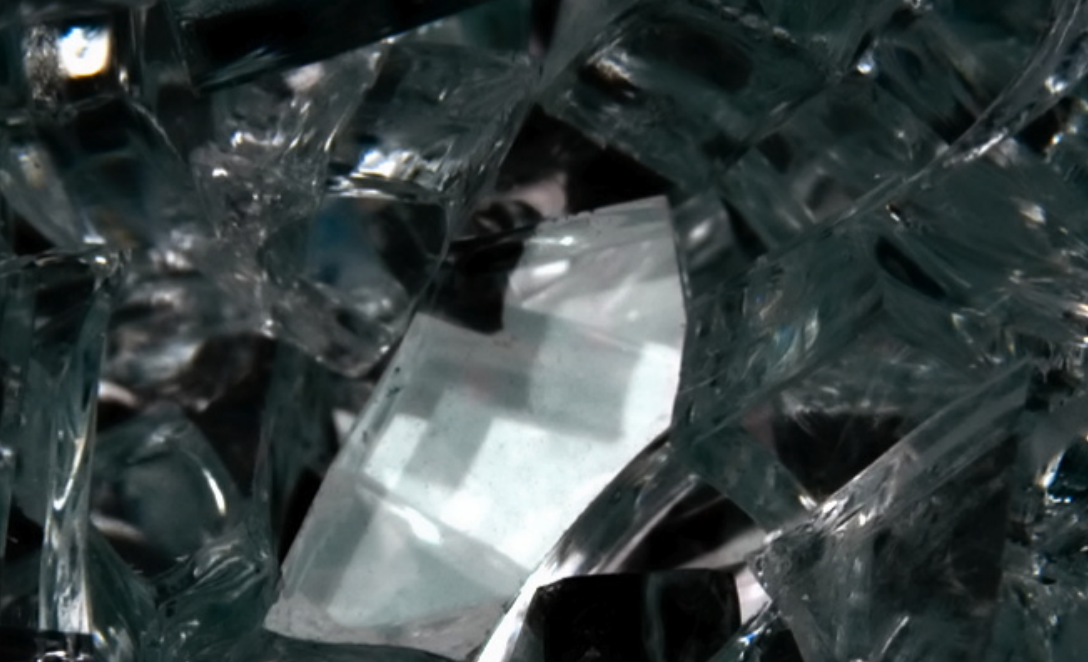

a.

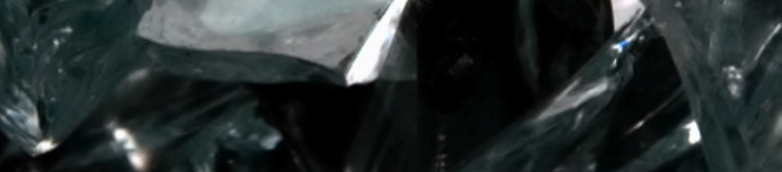

(1)

ON INDENTER BOUNDARY EFFECTS AT ELASTIC CONTACT

Denis Jelagin and Per-Lennârt Larsson

2
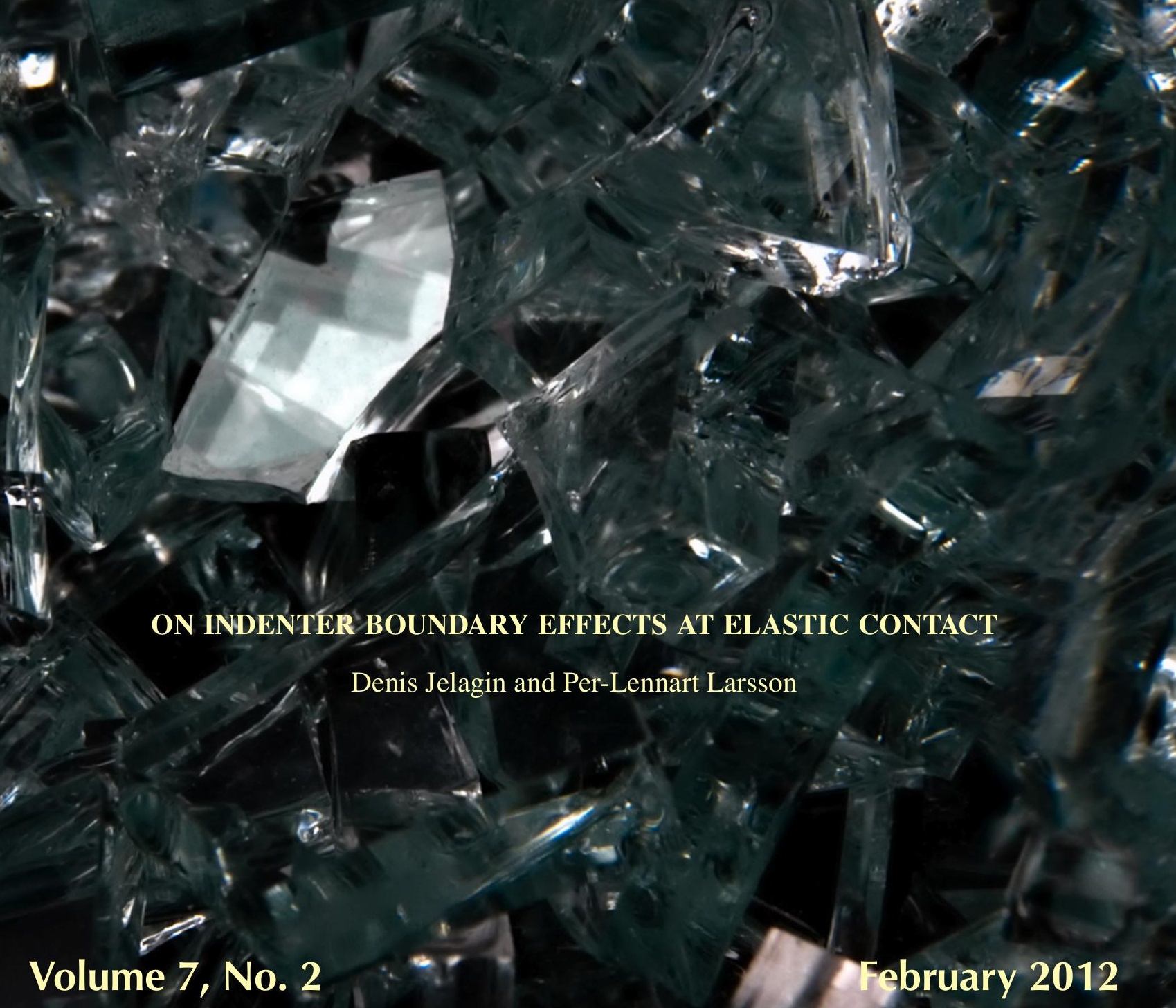


\title{
ON INDENTER BOUNDARY EFFECTS AT ELASTIC CONTACT
}

\author{
Denis Jelagin AND PER-LenNaRt LARSSON
}

\begin{abstract}
Axisymmetric contact problems at finite Coulomb friction and rounded profiles are examined for linear elastic solids. In previous analytical/numerical approaches to this problem often incremental procedures have been developed resulting in a reduced incremental problem corresponding to a rigid flat indentation of an elastic half-space. The reduced problem, being independent of loading and contact region, can be solved by a finite element method based on a stationary contact contour and characterized by high accuracy. Subsequently, with cumulative superposition procedures it is then possible to resolve the original problem in order to determine global and local field values. Such a procedure, when applied to for example to flat and conical profiles with rounded edges and apices, is exact save for the influence from boundaries close to the contact region. This influence could be exemplified by the indenter boundaries of a flat deformable profile with rounded edges indenting a linear elastic half-space. In the present analysis such effects are investigated qualitatively and quantitatively. In doing so, the results derived using previously discussed analytical/numerical approaches are compared with corresponding ones from full-field finite element calculations. Both local as well as global quantities are included in the comparison in order to arrive at a complete understanding of the boundary effects at elastic contact.
\end{abstract}

\section{Introduction}

Following the classical results by Hertz [1882] for normal frictionless contact between two linear elastic nonconforming bodies of elliptical profiles the corresponding problem was attacked for adhesive contact by Mossakovskii [1963] and Spence [1968] and for finite friction by Spence [1975a; 1975b]. Even though the Hertz formulation was based on linear elasticity and linear kinematics, the problem is indeed nonlinear due to the presence of a moving contact boundary. At finite friction further nonlinearities will evolve as stick-slip boundaries then have to be determined when partial slip occurs. In this context substantial progress was made by Spence [1975a; 1975b], who showed that under monotonic loading a single stickslip contour will evolve being independent of the contact profile provided it has a polynomial shape. More recently (see [Ciavarella and Hills 1999; Ciavarella 1999; Argatov 2002; Jaffar 2002; Storåkers and Elaguine 2005]], contact of various nonstandard profiles such as blunted cones and flat indenters with rounded edges, has been investigated. Besides a more general contact law behavior, the main intention has been to predict initiation of plastic flow or the occurrence of brittle fracture (also the contact behavior at nanoindentation is an interesting feature in this context; see [Fu 2006; Fu and Cao 2009]). Related experimental work has been presented in [Pau et al. 2006], for example.

Mossakovskii [1963] seems to have been the first to propose that normal contact problems at adhesive behavior may be attacked in two steps, by first solving the problem at an incremental advance and subsequently apply superposition. By emphasizing self-similarity for power-law profiles, further advances

Keywords: Contact mechanics, Elastic material, Friction, Indenter boundary effects. 
were made by Spence [1968; 1975a; 1975b]. Mossakovskii and Spence were mainly concerned with determination of surface tractions and displacements. Mossakovskii's analysis was later developed for indentation methods by Borodich and Keer [2004]. In case of axisymmetric and frictionless contact it was later shown in [Hill and Storåkers 1990] that complete field values may readily be determined by a solution for incremental fields followed by the cumulative superposition along radial paths. Numerically, such a procedure is at advantage as only a stationary mesh is required when finite elements are to be used. In view of self similarity principles applied by Hill et al. [1989] the strategy was utilized in full by Storåkers and Larsson [1994] for Norton creep by combining a finite element procedure with cumulative superposition. For the case of linear viscosity, the approach corresponds to linear elasticity though with incompressibility anticipated. In subsequent work, hereditary material behavior was treated in the same spirit for the case of plastic flow theory [Biwa and Storåkers 1995] and viscoplasticity [Storåkers et al. 1997], with finite friction also included [Carlsson et al. 2000] and oblique (nonnormal) loading [Larsson and Storåkers 2002].

Presently, with linear elastic contact at issue, history dependence evolves through the presence of finite friction. However, it was shown in [Storåkers and Elaguine 2005] for the case of monotonically increasing loading that history dependence is only fictitious and that the stick-slip contour relative to the external contact contour will be invariant for any contact profile provided that it is smooth and convex and the loading is axisymmetric and monotonically increasing. In the same paper a consistent and robust method was described to solve frictional normal contact problems at smooth and convex but otherwise arbitrary profiles with special emphasis put on the presence of finite friction causing partial slip between dissimilar solids. For profiles represented by monomials self-similarity will prevail as has been thoroughly discussed, for instance in [Borodich 1993] and [Borodich and Galanov 2002], in case of finite friction and also nonlinear elasticity. Analytically this is a convenient property but it will be lost for general profiles.

Usually, the normal contact problem sketched refers to one rigid member impressed into one elastically deforming. This requires only a half-space solution to be dealt with. If two of the contacting solids are deforming, formally a full-space solution with proper interface conditions needs to be mastered save for the degenerate case of two identical elastic materials. It has been pointed out by Mossakovskii [1963] and Spence [1968; 1975a; 1975b], however, that the contact tractions arising may be determined from a single half-space solution by using a tailored combination of material parameters for two dissimilar solids. When these interface conditions are captured, the respective fields of the two solids may be obtained individually.

The above described theoretical approaches and computational procedures, applied to the different indentation problems; rest, however, on the assumption that, at contact of rounded profiles, any effects from the boundary of the deformable indenter outside of the contact region are negligible. This may be so in many situations of practical interest but is from a theoretical point of view not immediately obvious and has been discussed for the 2D half-plane case by Banerjee et al. [2009]. Argatov [2010] considered the size effect associated with the finite dimensions of the indented sample, and the size effects associated with material length scales included in constitutive description where studied in some detail by Huang et al. [2006] and Harsono et al. [2011]. At axisymmetric conditions size effects related to the dimensions of the deformable indenter have not been studied in detail previously and, accordingly, they will be investigated in the present analysis for the case of linear elasticity and a flat cylindrical 
punch with rounded edges. The latter case was chosen as it is expected that these boundary effects may be most significant for such a situation. It should be emphasized that this effect should not be confused with effects due to elastic deformation of the indenters in the contact region. This is sometimes called the indenter elasticity effect and is usually and also here as outlined below, considered in the analysis by using modified elastic parameters. The problem will be examined in detail using the finite element method and in particular the commercial finite element package ABAQUS is relied upon. It should be emphasized that the importance of the presently discussed problem is not limited to elastic indentation problems but is also relevant at for example analysis of fretting fatigue crack nucleation [Hills and Dini 2006; Nowell et al. 2006]. An accurate description of the local particle contact problem is of principal importance in discrete element modeling (DEM) of mechanical behavior of granular media (see Cundall and Hart [1992], for example) and in several other DEM applications. This include such problems as micromechanical analysis of powder compaction Heyliger and McMeeking [2001; Martin and Bouvard [2003; Martin et al. [2003; Skrinjar and Larsson [2004] and micromechanical modeling of rock materials [Matsuoka and Yamamoto 1993], as the size of the bodies in contact may be comparable to the characteristic contact dimensions (see [Thornton and Antony 1998] and [Thornton and Lanier 1997], for instance).

\section{Formulation of the problem}

The geometry of the problem to be analyzed is depicted in Figure 1 along with the notation; it involves contact between a flat indenter with rounded edges and a half-space under monotonically increasing load. It should be noted that this also includes the special cases of a flat and spherical indenters, as

$$
b=a \quad \text { and } \quad b=0
$$

respectively in Figure 1. The two solids are in a general case elastically dissimilar. The indenter geometry is defined by the indenter radius, $w$, indenter height, $l$, along with the radius of the flat part, $b$, and the

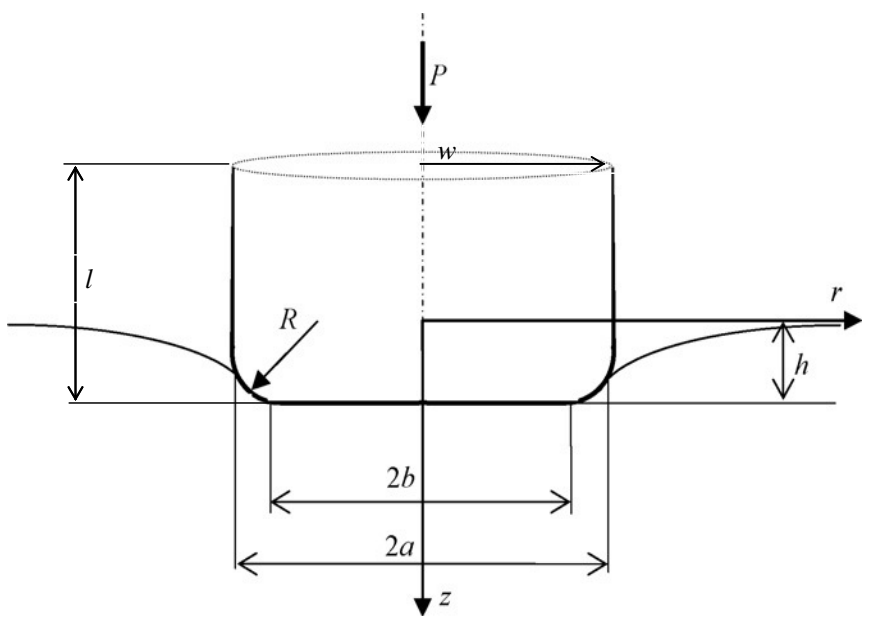

Figure 1. Geometry and notation of the problem of a flat indenter with a rounded corners indenting an elastic half-space. 
curvature radius of the round-off, $R$. It should be noted that in case of a nonrigid indenter, the Hertz theory of contact is strictly valid only when $w, l, R \gg a$.

In the analysis, quasi-static conditions are assumed to prevail and in the absence of body forces, equilibrium equations may be expressed as

$$
\sigma_{i j, j}=0
$$

and strain-displacement relations as

$$
\epsilon_{i j}=\left(\frac{1}{2}\right)\left(u_{i, j}+u_{j, i}\right)
$$

in obvious notation and linear kinematics assumed. Furthermore, Hooke's law in the elastic solids is expressed in the form

$$
\epsilon_{i j}=(1 / 2 G)\left(\sigma_{i j}-(v /(1+v)) \sigma_{k k} \delta_{i j}\right)
$$

where $G$ denotes the shear modulus and $v$ Poisson's ratio.

Coulomb friction is assumed to be valid at the interface between the elastic solids and the following boundary condition holds at points where frictional tractions are not sufficient to initiate tangential slip:

$$
\mu\left|\sigma_{z z}(r)\right|-\left|\sigma_{r z}(r)\right|>0, \quad \frac{\partial u_{r}(r, a)}{\partial a}=0, \quad r \leq c, \quad z=0
$$

and at points where slip occurs

$$
\mu\left|\sigma_{z z}(r)\right|-\left|\sigma_{r z}(r)\right|=0, \quad \frac{\partial u_{r}(r, a)}{\partial a} /\left|\frac{\partial u_{r}(r, a)}{\partial a}\right|=\sigma_{r z}(r) /\left|\sigma_{r z}(r)\right|, \quad c \leq r \leq a, \quad z=0 .
$$

In Equations (5) and (6) $c$ is the stick-slip radius.

Storåkers and Elaguine [2005] analyzed the present problem, depicted in Figure 1, and the corresponding one for a cone indenter with a rounded tip. In this investigation a reduced incremental problem was laid down based on a flat stationary boundary and modeled by finite elements. The reduced incremental problem concerned a rigid flat die indenting an elastic half-space. Subsequently, the original problem was readily solved by cumulative superposition as relative stick-slip contours proved to be invariant for any smooth and convex profile. As a consequence, in case of a rigid indenter, complete displacement and stress fields may be superposed for different contact profiles provided that monotonic loading prevails. Accordingly, when the interior fields are to be determined by for example a finite element method only a half-space solution is required.

When two dissimilar elastic solids are in contact solutions for interior fields are in general required in a full space. It has been shown, however, by Mossakovskii [1963] and Spence [1975b], that a half-space solution will still suffice to determine surface values. As explained in [Storåkers and Elaguine 2005], following [Spence 1975b], the stress state in the contact region between two elastic bodies is equivalent to that arising from contact between a rigid indenter and an elastic half-space with material parameters modified according to the relations:

$$
\frac{1-v_{m}}{G_{m}}=\frac{1-v_{1}}{G_{1}}+\frac{1-v_{2}}{G_{2}}, \quad \frac{1-2 v_{m}}{2 G_{m}}=\frac{1-2 v_{1}}{2 G_{1}}+\frac{1-2 v_{2}}{2 G_{2}}
$$


where $G_{m}, v_{m}$ are the modified elasticity parameters for the reduced rigid-elastic problem and $g_{i}, v_{i}(i=$ $1,2)$ are the elasticity parameters for the original two bodies in contact.

Thus, the resulting contact tractions may be directly determined by aid of a half-space solution procedure described in [Storåkers and Elaguine 2005]. As a result, two uncoupled problems pertinent to dissimilar half-spaces with prescribed normal and tangential stress distributions are obtained and the complete internal stress fields may be subsequently generated by two harmonic potentials as explained in detail in e.g. [Hills et al. 1993].

Accordingly, from the discussion above it is clear that the solutions to the contact problems described can be derived in a computationally favorable way from the solution of a reduced incremental problem with a stationary contact boundary corresponding to a flat rigid punch indenting an elastic half-space. However, due to the fact that the reduced incremental problem is rigid-elastic, unavoidable effects on global and local quantities from the boundaries of the indenter are not accounted for. The validity of this assumption in the case when the indenter has dimensions comparable with the contact size will be investigated here. In particular the attention will be focused on the influence of the relative indenter radius, $w / a$, on the contact conditions. In order to ensure that other indenter geometrical parameters do not contribute to the deviation from the Hertz theory (and to ensure the validity of the rigid-modified elastic solution), the indenter height, $l$, and the curvature radius, $R$, will be kept sufficiently large, as compared to the contact radius, in all of the simulations. This of course also indicates that the indentation depth is much smaller than the contact radius.

Provided that the dimensions of contacting bodies are large compared to the contact size $(R / a, l / a$, $w / a \gg 1)$, the pressure and shear tractions distributions obtained at elastic-elastic and rigid-modified elastic formulations should be identical. Furthermore, the relative stick-slip radius, $c / a$ is then invariant of indenter geometry as well as of depth of indentation and depends only on composite elastic coefficients and coefficient of friction, as shown for the case of smooth and convex, but otherwise arbitrary profiles by Storåkers and Elaguine [2005]. On the other hand, when the indenter dimensions are close to the contact radii, the invariance properties are lost and pressure and shear traction distribution are influenced by the global stress-strain state in the indenter, which is in turn controlled by the material parameters of the contact pair; the details of indenter geometry and of the load application. It seems to be impossible to establish a complete set of parameters describing any possible combination of the above. One would rather have to rely on numerical modeling to find out what exactly happens in each particular contact configuration. The main intention of the present study is to establish the limits of the validity of the rigid-modified elastic formulation with respect to the relative indenter radius, $w / a$. Situations with $w / a$ close to 1 are considered to be of practical interest as they may be found in the contact configuration with flat indenters and flat indenter with rounded corners.

Contact between two dissimilar elastic bodies, as depicted in Figure 1, will be investigated in two different ways: by prescribing the respective elastic constants to each of the bodies and by prescribing high values to the elastic parameters of the indenter and modifying the elasticity parameters of the halfspace according to (7). The discrepancy between the two solutions indicates the indenter boundary effects at issue presently.

In the present study an ABAQUS-based finite element method is used to analyze frictional contact between two dissimilar elastic bodies, as depicted in Figure 1, drawing upon the experience gained during previous and similar analyses [Elaguine et al. 2006; Jelagin and Larsson 2008a; 2008b]. In Figure 2 the 


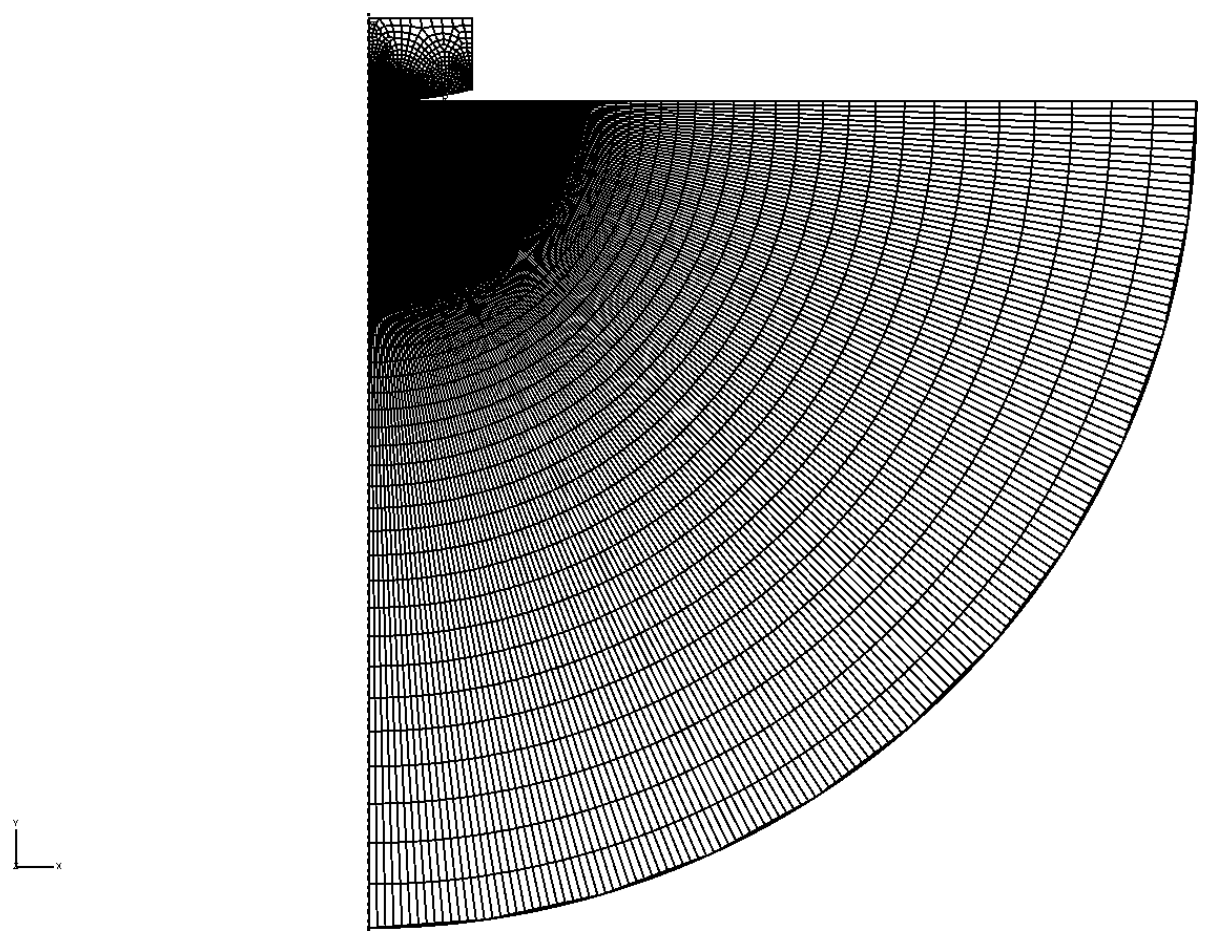

Figure 2. Finite element mesh; indenter with spherical contact profile.

finite element mesh is shown for the case of a spherical indenter with axisymmetry taken into account and with eight-noded isoparametric quadrilateral elements used. The contact pair is shown in Figure 2 for the particular case of the indenter with spherical contact profile and with $w=25 a_{\text {rigid_sphere. One }}$ may notice the domain with especially dense mesh in the vicinity of the contact region with the element size chosen to have at least 50 elements in contact. The outer boundary of the half-space was introduced to be at least 200 times the maximum contact radius in order to avoid remote boundary effects. At the outer boundary of the half-space the horizontal displacements were free to move while the vertical ones were set to vanish. The outer boundary of the indenter was set free outside the contact region. The load was applied by prescribing a uniform vertical displacement to the indenter's upper boundary.

A surface based contact formulation was used to model the interaction between two elastic bodies. At normal contact behavior, a hard contact formulation was used, where surfaces may not penetrate each other. To model the basic Coulomb friction Lagrange multiplier method was employed which allowed for sticking constraints to be enforced exactly.

In order to validate the numerical procedure developed presently, the global and local field values found at frictionless contact between a linear elastic half-space and rigid flat and spherical indenters were compared with the analytical solution due to Hertz [1882]. The global values were found to be accurate up to $0.3 \%$, while the accuracy of the local field values was found to be within $1 \%$.

The global and local field values obtained at frictional contact between a rigid indenter and a linear elastic half-space were compared to the ones found with an alternative computational procedure developed by Storåkers and Elaguine [2005]. Results were found to agree with 1\% accuracy. As shown 


\begin{tabular}{|c|cc|cc|}
\hline & \multicolumn{2}{|c|}{ elastic-elastic contact } & \multicolumn{2}{c|}{ rigid-elastic contact } \\
& $E(\mathrm{GPa})$ & $v$ & $E(\mathrm{GPa})$ & $v$ \\
\hline Indenter & 200 & 0.300 & 1000 & 0.499 \\
Halfspace & 70 & 0.220 & 47.2 & 0.377 \\
\hline
\end{tabular}

Table 1. Material parameters for the contact pair.

by these authors for the case of smooth and convex but otherwise arbitrary profiles and monotonically increasing load, the stick-slip radius is invariant of the loading and profile geometry. Presently, it has been found at monotonic frictional indentation of rigid flat, spherical and flat and rounded indenters that the relative stick-slip radius was almost constant and never varied more than one element size.

\section{Results and discussion}

The effect of indenter elasticity on a contact induced stress state is investigated presently for the case of a steel indenter pressed into a glass halfspace. The elasticity parameters for the contact materials are given in Table 1, along with material parameters for the equivalent rigid-elastic contact pair. The interfacial friction coefficient, $\mu$, is set to 0.1 as measured by Elaguine et al. [2006].

Numerical studies are performed for the case of flat and rounded contact profiles as shown in Figure 1. The relative radius of the flat part, $b / a$, is varied between 0 and 1 giving in the limits spherical and flat indenters respectively. The indenter height, $l$, is kept fixed being 7 times the maximum contact radii attained during simulations, $l \approx 7 a_{\mathrm{MAX}}$. The round-off radius of the rounded part is kept fixed at $R \approx 30 a_{\mathrm{MAX}}$. The validity of the Hertz theory assumption regarding the contact area being small as compared to indenter dimensions is then controlled by the ratio between indenter radius, $w$, and contact area radius, $a$. The analysis is performed presently for the cases of $1 \leq w / a \leq 50$, where the geometries with high $w / a$ ratios are considered to be close to the Hertz theory, and the lower ratios represent an indenter with dimensions finite as compared to the contact size. The indenter shown in Figure 3 is used in simulations to represent a perfectly flat punch with $w / a>1$; it consists of two cylinders the first one of radius $a$ and length $l$, and the second one with radius $w-a$ and a bit shorter so it does not come in

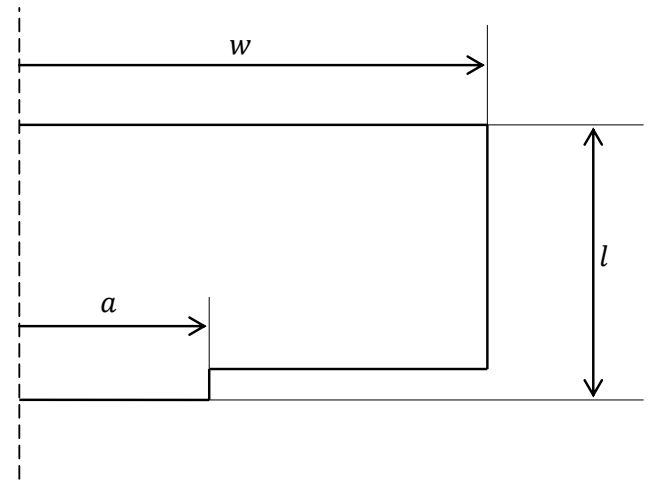

Figure 3. The flat indenter with $w \gg a$. 


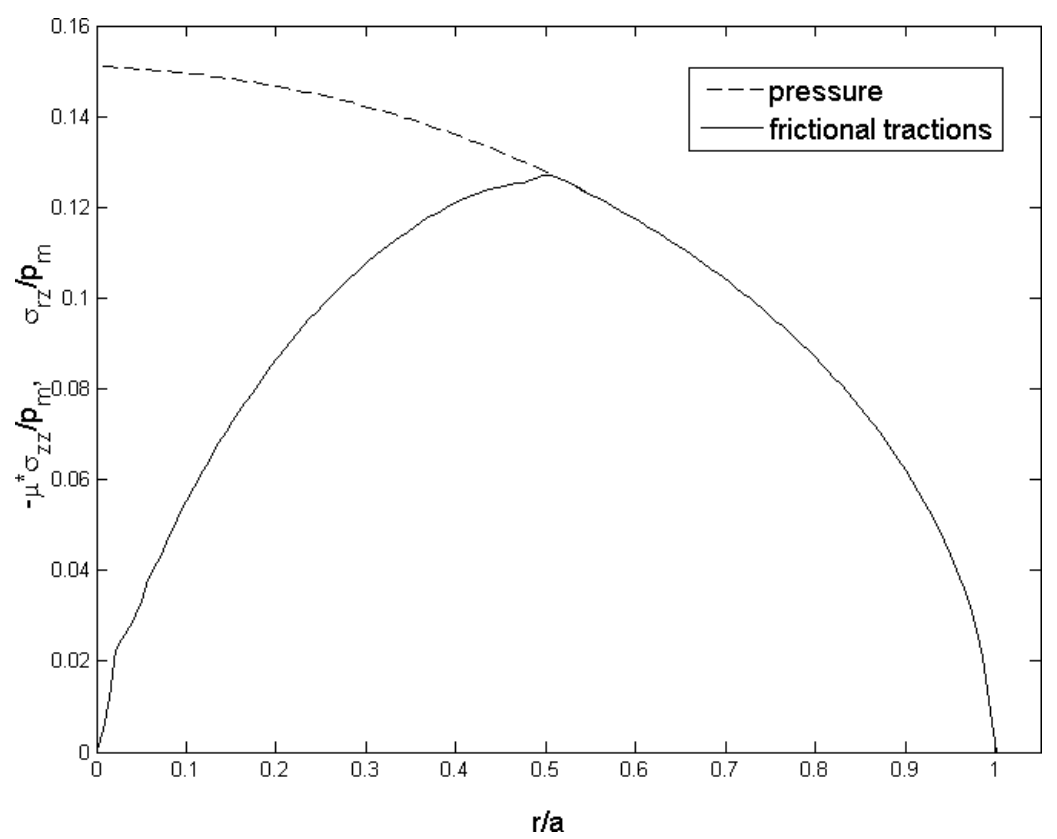

Figure 4. Normal and tangential tractions at spherical indentation $(w>>a)$.

contact with the specimen. It has to be pointed out that in Figure 3 proportions are not kept for illustrative reasons, in the simulations the first cylinder had the length $l=7 a_{\mathrm{MAX}}$ and the second cylinder had the length of $l-0.05 a_{\mathrm{MAX}}$.

In all the simulations performed the load was applied in displacement control mode, by prescribing a uniform vertical displacement, $\delta$, to the upper boundary of the indenter. All comparative studies have been performed at fixed $\delta \approx 0.02 a_{\mathrm{MIN}}$ (chosen to be small compared to the contact radii in all the simulations). In the presentation below, results pertinent to spherical indentation are depicted in Figure 4, flat punch results are depicted in Figures 5-9 and in Figures 10-12 a comparison is made between the results for different indenter geometries. Contact features such as pressure distribution, tangential tractions, vertical and horizontal displacements, contact area and stick-slip radius are considered and pertinent results presented.

In Figure 4 then, the pressure and frictional traction distributions are shown, for the case of a spherical indenter $(b=0), w / a>50$, and elastic-elastic contact. The distributions are normalized with the mean pressure, $p_{0}=P /\left(\pi a^{2}\right)$, and for illustrative purposes the pressure distribution is multiplied by the friction coefficient. Obviously, the region where the distributions coincide correspond to the slip region; see (5) and (6). The relative stick-slip radius in the present case was found to be $c / a=0.5$, which is well within one element length from the 0.497 given by the analytical formula developed by Spence. It has been found that for the case of $w / a>50$, normal and tangential tractions computed with the equivalent rigid elastic formulation differ less than $0.5 \%$ from the results obtained with the elastic-elastic model for all the contact geometries studied, i.e., $0 \leq b / a \leq 1$.

Furthermore, it has been shown by Storåkers and Elaguine [2005] that the relative stick-slip radius is independent of profile geometry provided that profiles are smooth and convex. Presently, in all the 


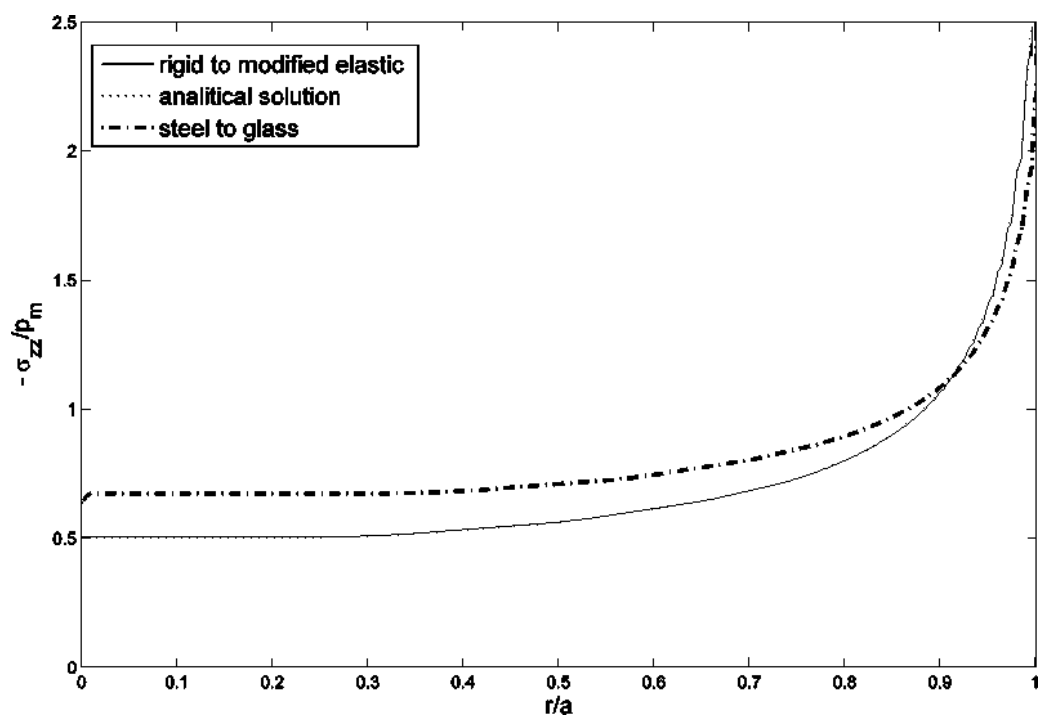

Figure 5. Pressure distribution at frictionless flat punch indentation $(w=a)$.

simulations performed for the big indenters $(w / a>50)$, the stick-slip radius was found approximately constant and equal to 0.5 both for elastic-elastic and equivalent rigid-elastic formulations.

In Figure 5 normalized pressure distributions are shown for the frictionless flat punch indentation, $(b / a=w / a=1)$. Distributions obtained with elastic-elastic and equivalent rigid-elastic formulations are presented along with the analytical solution; see [Johnson 1985]. The figure shows that the pressure distribution obtained with a rigid indenter basically coincides with the analytical solution. The distribution corresponding to the steel to glass contact deviates however from the analytical and rigid elastic distribution; as one may observe in Figure 5 the pressure in the middle of the contact area is approximately $35 \%$ higher for the elastic-elastic as compared to the rigid-elastic case. Furthermore, at the vicinity of the contact boundary indenter elasticity results in somewhat lower pressure. This difference between the two sets of results is due to the fact that the steel indenter undergoes significant deformation under action of high pressure at the vicinity of the contact boundary and the resulting contact geometry deviates from the perfectly flat punch. This is shown in Figure 6, where the vertical displacements on the surface of the halfspace are presented normalized with maximum indentation depth. It may be seen that displacements induced in the contact area by a steel punch deviates from the one induced by a rigid punch by approximately $12 \%$ at the contact boundary. The simulations have also been performed with steel indenters having heights $l / a=1$ and 5, the shape of vertical surfaces displacements were found to be independent of height. However, in simulations of flat punch indentation performed at $w / a \gg 1$, the indenter elasticity was found to have a very minor effect on the pressure distribution and surface displacement profiles, resulting in approximately $1 \%$ variation from the rigid-modified elastic case. This indicates that the effect of local indenter deformations on the pressure and frictional tractions distributions is minute.

Regarding the results in Figures 5 and 6 for frictionless indentation, it is important to emphasize that the influence of friction on the pressure distribution, Figure 5 and the vertical surface displacements, Figure 6, was found presently to be very small. This has also been shown in several previous studies; see, for example, [[Hills and Sackfield 1987; Andersson 1996; Storåkers and Elaguine 2005]]. Consequently, 


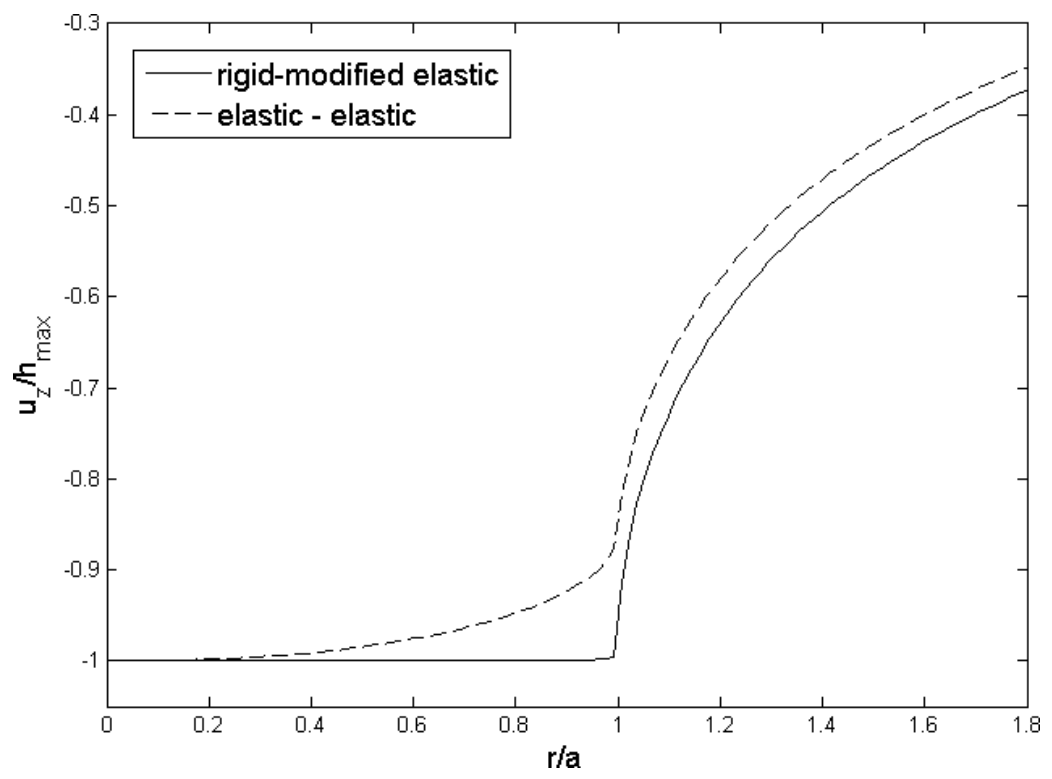

Figure 6. Vertical surface displacements at flat punch indentation, rigid-elastic vs elastic-elastic formulation.

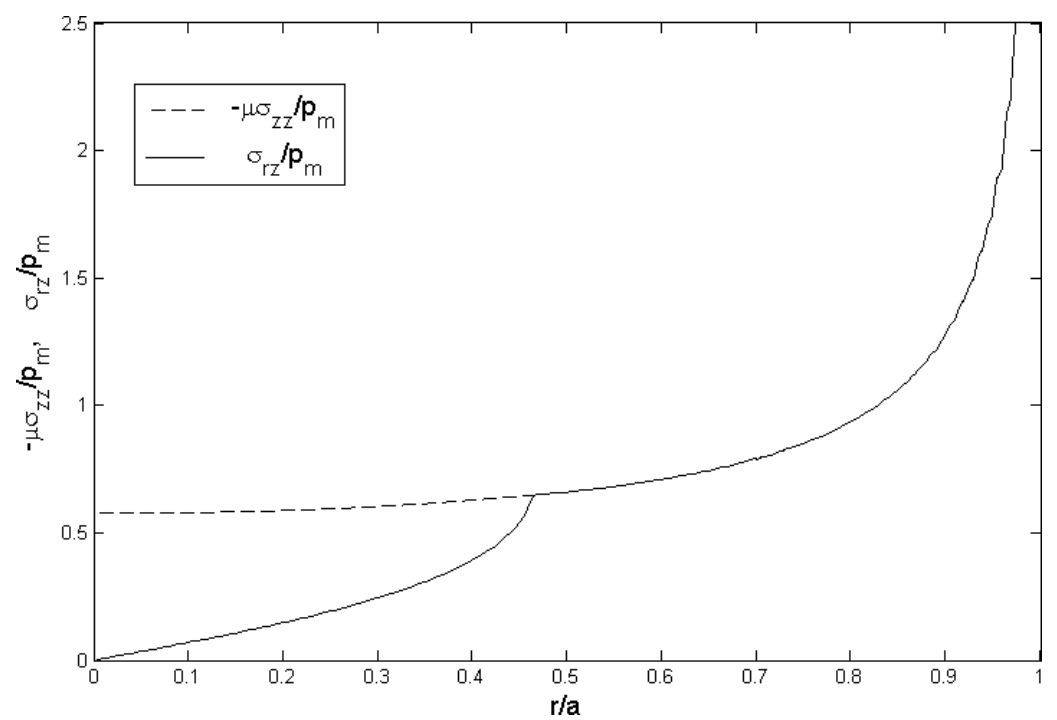

Figure 7. Normal and tangential tractions, flat punch indentation at finite friction, rigidelastic contact.

the impact of the finite size of the elastic indenter on these quantities would be the same for frictionless and finite frictional cases.

Figures 7 and 8 examine frictional flat punch indentation with rigid-elastic and elastic-elastic solutions respectively. Normalized shear tractions are presented, along with normalized pressure distributions multiplied by friction coefficients. It may be observed in Figure 7 that the relative stick-slip radius for the rigid flat punch is approximately 0.5 , equal to the one found for profiles with $w / a>50$. However, as 


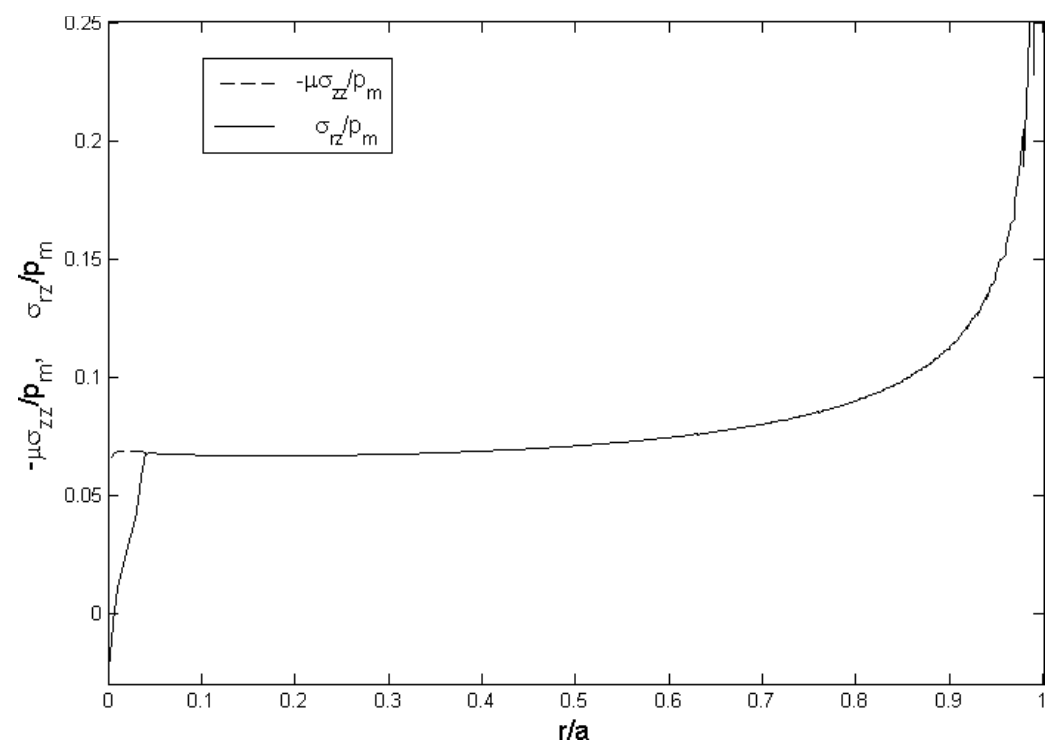

Figure 8. Normal and tangential tractions, flat punch indentation at finite friction, elastic-elastic contact.

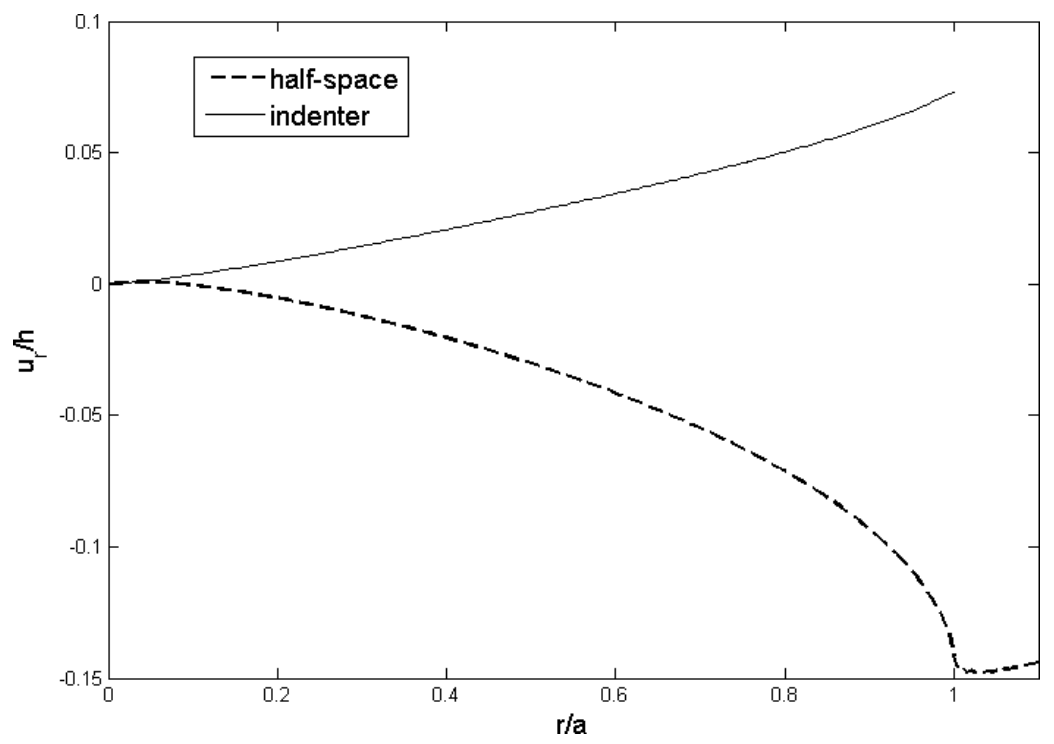

Figure 9. Horizontal surface displacements at frictional flat punch indentation.

shown in Figure 8, the relative stick-slip radius found at steel to glass contact is much smaller, approximately 0.04. In Figure 9 the horizontal displacements on the surfaces of the steel indenter and the glass halfspace are shown normalized with the depth of indentation. It may be seen that while the material in the glass specimen tend towards the center of the contact area, the steel indenter undergoes some elastic expansion with the material moving away from the axis of symmetry. This elastic expansion gives rise to additional shear tractions on the interface which result in a much smaller stick zone radius. 


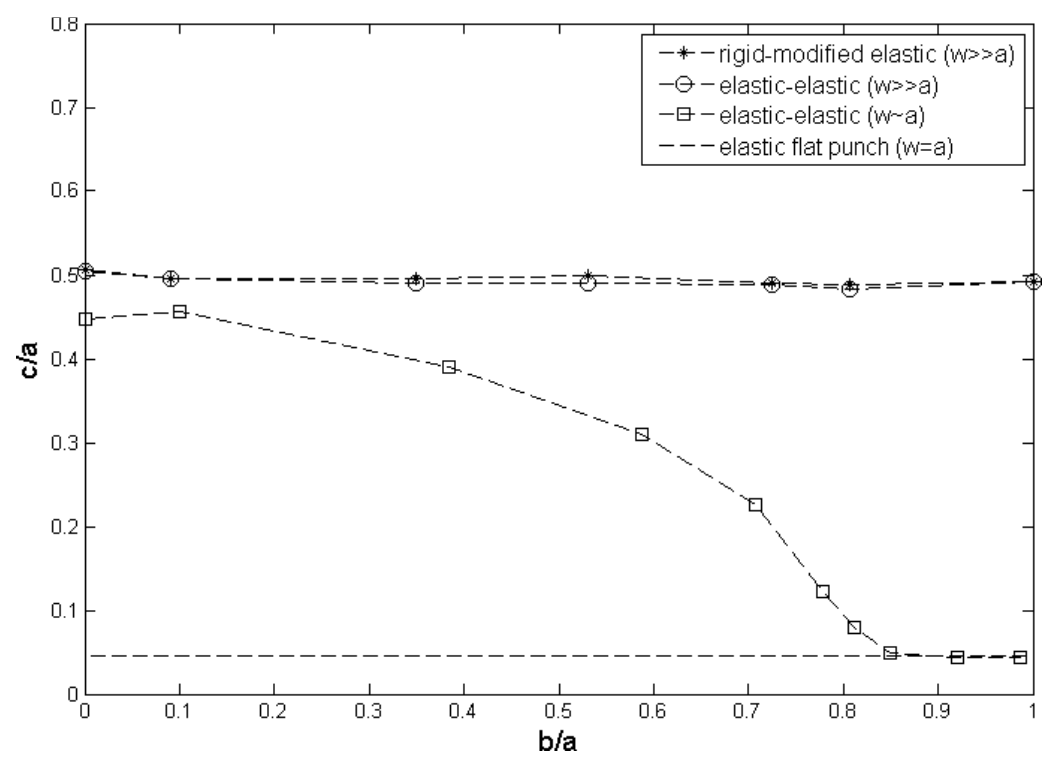

Figure 10. Relative stick-slip radii at flat and rounded contact.

As seen from the study of the limiting cases of $w / a>50$ and $w / a=1$ (Figures 5-9) the indenter elasticity may have a profound influence on the induced pressure and frictional tractions at dissimilar elastic contact. In order to examine this effect further the contacts between flat and rounded indenters, with a size comparable with the size of the contact area, have been studied. The indenter radius has been set to three times the contact area at rigid spherical indentation $w=a_{\mathrm{MAX}}$. The radius of the flat part, $b$, has been varied while the indenter radius was kept constant.

In Figure 10 the relative stick-slip radii, $c / a$, obtained at elastic-elastic indentation with a finite flat and rounded indenter are shown as a function of $b / a$. Also in Figure 10 the stick-slip radii are presented for flat and rounded indenters with $w \gg a$ as well as for the elastic-elastic flat punch indentation at $w=a$. As one may observe in Figure 10 the stick-slip radii at $w \gg a$ are invariant of contact geometry and of contact formulation and are approximately equal to $0.5 a$. The same stick-slip radii have been found at rigid-modified elastic contact for the flat and rounded indenter with $w=3 a_{\text {rigid_sphere, }}$ results are not shown in Figure 10 for brevity. At elastic-elastic contact however this invariance is lost. It may be seen that for finite indenters with shapes close to spherical $(b / a<=0.1)$ the stick-slip radius deviates approximately $10 \%$ from the rigid-elasic case. As $b / a$ increases the stick-slip radius decreases and for $b / a>0.8$ it is equal to the one at elastic-elastic flat punch indentation.

The results presented in Figure 10 indicate the existence of the indenter boundary effect at indentation of a flat and rounded punch with dimensions comparable to the contact radius. The $b / a$ variation was achieved presently by varying the size of the flat part with respect to the indenter size, i.e. $b / a$ varying between 0 and 1 corresponds to $b / w$ varying between 0 and 1 and $w / a$ varying from 3 to 1 .

In Figure 11 the contact area radii at spherical and flat and rounded elastic-elastic contacts are shown as function of $w / a$. Results are normalized with the corresponding contact area radii obtained at equivalent rigid-elastic contact. As it may be observed in Figure 11 the contact radii obtained with elastic-elastic and rigid-elastic formulations coincide for at least $w>10 a$. At relative indenter sizes $w<10 a$ the contact 


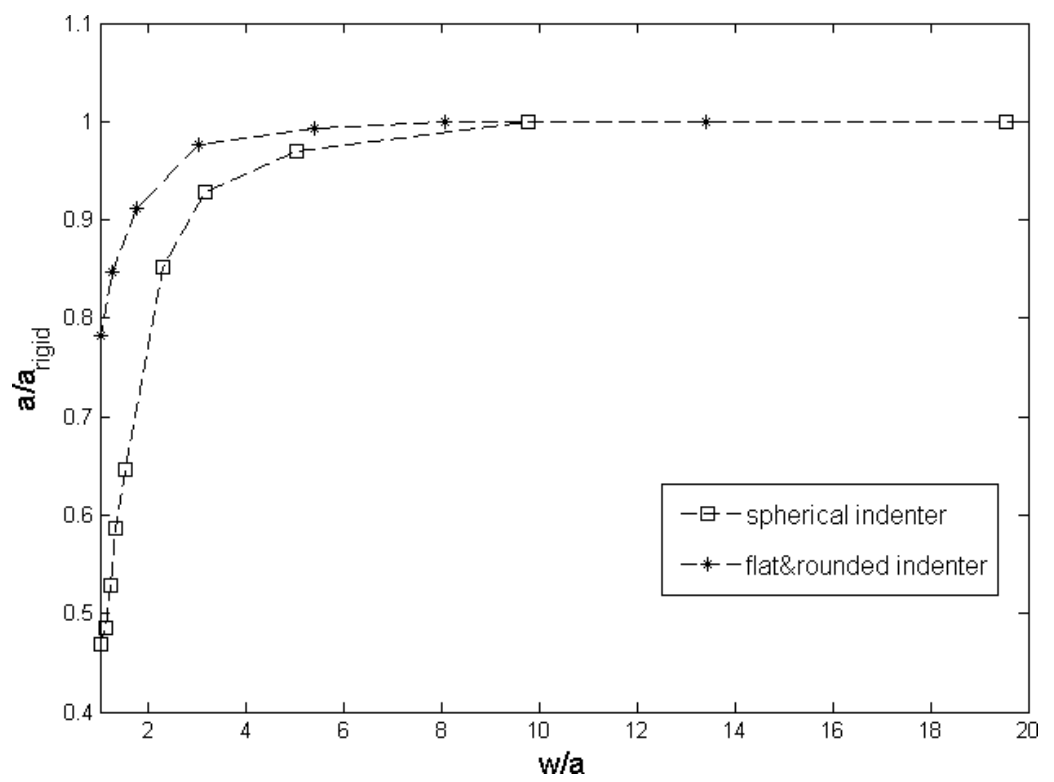

Figure 11. Contact area at elastic-elastic contact spherical and flat and rounded indenters.

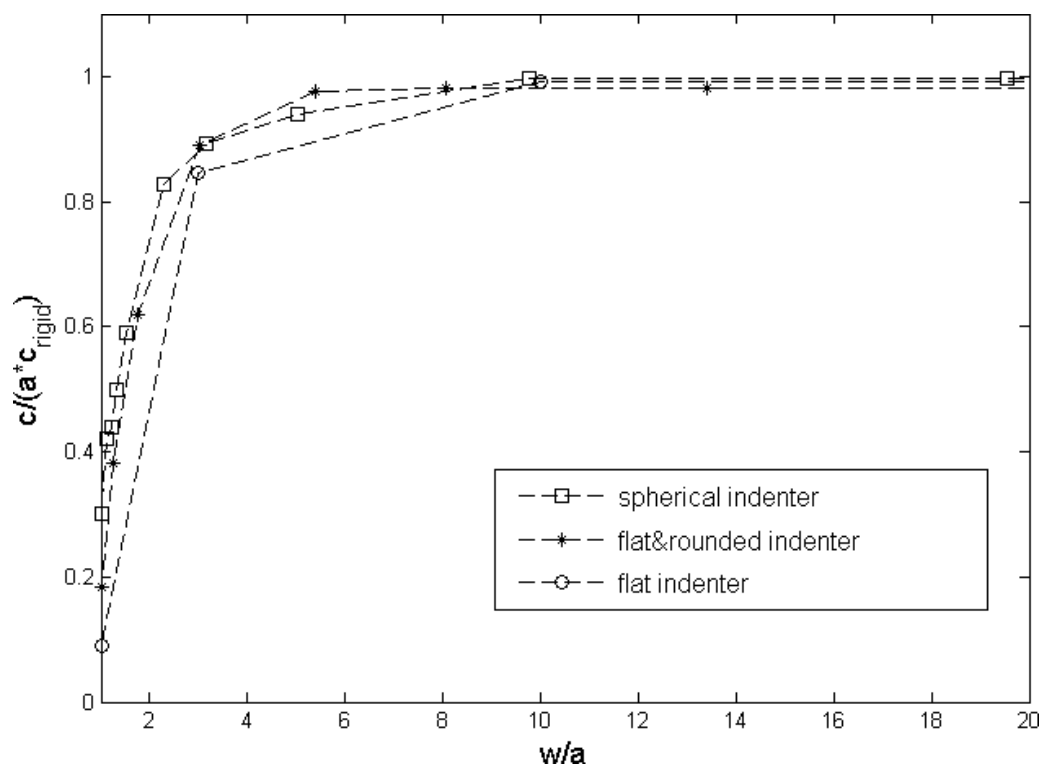

Figure 12. Stick-slip radii at elastic-elastic contact as a function of indenter size relative to the contact area.

area is somewhat smaller than the one at rigid-elastic contact, the amount of reduction depending on the contact geometry. The difference is however less than $10 \%$ for $w>4 a$ in the spherical case and for $w>2 a$ for the flat and rounded case. For the flat and rounded contact the radius of the flat part was taken to be equal to the contact area at rigid spherical indentation $b=a_{\text {rigid_sphere, }}$ the relative size of the flat part, $b / a$, was varying between 0.54 for $w>=6 a$ and 0.7 for $w=a$. The reason behind the 
sharp decrease of the contact area at small values on $w / a$ is the fact that the effect of indenter stiffness is not adequately accounted for by the reduced modulus of the halfspace. The particular indenter shape investigated has $l / a=20$, and at small $w / a$ the indenter deforms significantly more than predicted by Hertz contact theory.

In Figure 12 the relative stick-slip radii at spherical, flat and flat and rounded elastic-elastic contact are shown as function of $w / a$. As in Figure 11 results are normalized with the ones obtained at rigid elastic contact. One may observe that indenter elasticity doesn't influence the stick-slip radius for $w>10 a$, at $w / a<10$ the stick region starts to decrease and also becomes geometry dependent.

It has to be emphasized that the results depicted in Figures 10-12 relate to the effect that the global indenter stress state has on the pressure and frictional tractions distributions. Therefore, as the selfsimilarity is lost here, the results presented are strictly valid only for the particular geometries investigated; altering the indenter height, elastic properties and/or load application mode would alter the effect. Rodriguez et al. [2011] evaluated the effect of the elastic indenter deformation on the instrumented indentation measurements. They preformed FE simulations of diamond sphere frictionless indentation into different elastic materials at the following contact parameters $w / a \approx 3.2, l / a \approx 3.2, R / \delta_{\max }=10$, $\delta_{\max }$ being the mutual approach distance, and $a$ is the contact radius estimated based on Hertz theory. Analogous to the present study, they ran comparative analysis with elastic-elastic and rigid-modified elastic contact simulations. They reported that indenter elasticity taken into account results in a slight increase of the contact radius as compared to the rigid-elastic solution; in particular, for the case of $E_{\text {specimen }} / E_{\text {indenter }}=0.39$ they found $2.1 \%$ increase of the contact radius. As it may be seen in Figure 11, an approximately $7 \%$ reduction in the contact area radius is observed presently when indenter elasticity is taken into account at $w / a=3.2$. The discrepancy between present results and the ones Rodriguez et al. is due to the fact that the rest of contact parameters are different; present simulations are performed at $E_{\text {specimen }} / E_{\text {indenter }}=0.39$ and $l / a \approx 20, R / \delta_{\max }=1 e 3$. In order to check the effect of indenter height on the contact radius the analysis has been performed presently at $l / a=w / a \approx 3$ keeping the rest of parameters as in other simulations and it has been found that the contact radius increases approximately $1.5 \%$ in this case due to indenter elasticity. This is close to the $2.1 \%$ found by Rodriguez et al., with the remaining difference most likely due to differences in curvature radii and material properties used.

Results presented in Figures 11 and 12 indicate that indenter boundaries significantly affect the distributions of pressure and frictional tractions only when $w$ is less than say $4 a$, the exact range depending of course on indenter geometry. In case of the contact geometries close to spherical $(b \rightarrow 0)$ the loads required to produce $w<4 a$ will induce significant plastic deformations or fracture in most of the practically interesting contact pairs.

Contact at flat and rounded profiles with a flat part radius comparable with the indenter radius may result in $w / a \approx 1$ even at moderate loads. Pau et al. [2006] used ultrasound based technique to examine the contact geometry at indentation with a steel flat indenter with rounded corners into a steel plate. The indenter used had a radius of $10 \mathrm{~mm}$ and the radius of the flat part was $2.5 \mathrm{~mm}$. The reported measurements were performed at a load level which resulted in $a \approx 4 \mathrm{~mm}, b / a \approx 0.63$ and thus in $w / a \approx 2.5$. As shown in Figure 11 the contact area for the flat and rounded indenter at $w / a=2.5$, $b / a=0.57$ is approximately $5 \%$ smaller as compared to the one obtained at rigid-modified elastic contact. The relative stick-slip radius for this geometry is shown in Figure 12 and is approximately $78 \%$ of the one found at rigid-modified elastic contact. At smaller loads giving $b / a \approx 1$, the indenter geometry used 


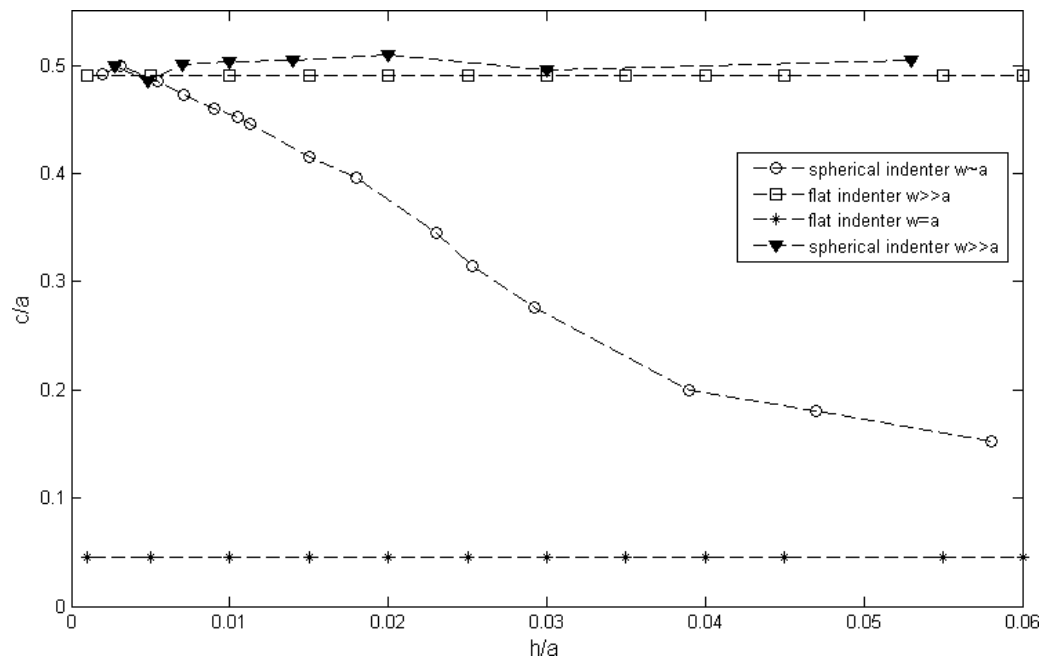

Figure 13. Stick-slip radii at elastic-elastic contact as a function of relative indentation depth.

by Pau et al. [2006] would result in $w / a \approx 4$. In this case, based on the results presented in Figure 11 the effect of the indenter boundaries on the contact area will be very minor. The relative stick-slip radius will be reduced by approximately $5 \%$ as compared to the rigid-modified elastic formulation.

As it has been pointed by Chaudhri in relation to the postprocessing of nanoindentation tests data (see also Lim and Chaudhri [2003]), the Boussinesq [1885] and Sneddon [1965] solutions are strictly valid only for rigid indenters. Results presented in Figures 5-8 substantiate this observation for the case of a flat cylindrical indenter $w=a$ - the rigid-modified elastic formulation is not capable of properly accounting for the elastic deformation of the indenter. However, based on the results in Figure 12 and the related discussion it appears to be possible to use the rigid-modified elastic formulation to evaluate the frictional indentation with a elastic flat-ended punch, provided that it's geometry results in $w / a \gg 1$.

In Figure 13, the stick-slip radii found at elastic-elastic contact are shown as a function of the relative indentation depth. Results in Figure 13 are given for flat indenters with $w \gg a$ and $w=a$, as well as for spherical indenters with $w \gg a$, and $w \sim a$. In the case of a spherical indenter with finite dimensions the relative indenter radius, $w / a$, varies with increasing depth of indentation between 11.72 and 1.05. As one may observe in Figure 13, the relative stick-slip radii for flat indenters and for the spherical indenter with $w \gg a$ remain approximately constant at relative indentation depths varying between $2 e-3$ and $6 e-2$. In case of a spherical indenter with $w \sim a$ the stick-slip radius decreases from $0.5 a$ to $0.15 a$, which agrees well with approximately the 70\% decrease in stick-slip radius depicted in Figure 12.

\section{Concluding remarks}

The influence of the boundary effects on the frictional contact of dissimilar elastic solids has been examined presently for the case of flat and rounded contact profiles. In particular, the effect of relative indenter size, $w / a$ on the pressure and tangential tractions distribution has been evaluated based on the comparison between elastic-elastic and rigid-modified elastic contact formulations. In general, it has been found that the results obtained with these two formulations start to deviate significantly at $w / a<4$. This indicates 
that the approximation given in (7) does not account properly for the indenter elasticity at small $w / a$, and the contact tractions distributions depend than on the global stress state in the indenter. Thus, solution of the coupled problem taking into account the indenter geometry and constraints is required in order to accurately describe the contact between specimen and the indenter with the dimensions close to the contact area radius.

The practically important class of contacts with $w / a \approx 1$ are the complete or nearly complete contacts, i.e. flat indenters with rounded corners and $b / a \approx 1$. In these situations indenter boundary effects should be accounted for in order to obtain an accurate description of contact interactions. One practically important case where this effect is of significance is indentation testing with flat punch [Chaudhri 2001]. At the same time most of the practically important contacts at profile geometries close to spherical $b / a<<1$ will have the indenter dimensions much bigger as compared to the contact radius as long as the load is relatively small and linear elasticity prevails. The boundary effects will however affect contact conditions for these geometries in case of multiple contacts located close to each other as may be the case in micromechanical simulations with discrete element method.

In the present study, the effect of local elastic deformations of the indenter on the normal and tangential tractions was found to be minute for all the geometries investigated. Thus, it may furthermore be concluded that the computational procedure developed by Storåkers and Elaguine [2005] based on self-similarity can be used to accurately evaluate frictional dissimilar elastic contact at flat and rounded contact profiles at least for $w / a>4$.

\section{References}

[Andersson 1996] M. Andersson, "Stress distribution and crack initiation for an elastic contact including friction", Int. J. Solids Struct. 33:25 (1996), 3673-3696.

[Argatov 2002] I. I. Argatov, "The pressure of a punch with a rounded edge on an elastic half-space", J. Appl. Math. Mech. 66:4 (2002), 637-643.

[Argatov 2010] I. I. Argatov, "Frictionless and adhesive nanoindentation: asymptotic modeling of size effects", Mech. Mater. 42:8 (2010), 807-815.

[Banerjee et al. 2009] N. Banerjee, D. A. Hills, and D. Dini, "The derivation and application of a semi-infinite flat and rounded asymptotic frictionless contact”, Int. J. Mech. Sci. 51:9-10 (2009), 662-666.

[Biwa and Storåkers 1995] S. Biwa and B. Storåkers, "An analysis of fully plastic Brinell indentation”, J. Mech. Phys. Solids 43:8 (1995), 1303-1333.

[Borodich 1993] F. M. Borodich, “The Hertz frictional contact between nonlinear elastic anisotropic bodies (the similarity approach)", Int. J. Solids Struct. 30:11 (1993), 1513-1526.

[Borodich and Galanov 2002] F. M. Borodich and B. A. Galanov, "Self-similar problems of elastic contact for non-convex punches", J. Mech. Phys. Solids 50:11 (2002), 2441-2461.

[Borodich and Keer 2004] F. M. Borodich and L. M. Keer, "Evaluation of elastic modulus of materials by adhesive (no-slip) nano-indentation", Proc. R. Soc. Lond. A 460:2042 (2004), 507-514.

[Boussinesq 1885] J. Boussinesq, Applications des potentiels à l'étude de l'équilibre et du mouvement des solides élastiques, Gauthier-Villars, Paris, 1885.

[Carlsson et al. 2000] S. Carlsson, S. Biwa, and P.-L. Larsson, "On frictional effects at inelastic contact between spherical bodies", Int. J. Mech. Sci. 42:1 (2000), 107-128.

[Chaudhri 2001] M. M. Chaudhri, "A note on a common mistake in the analysis of nanoindentation data", J. Mater. Res. 16:2 (2001), 336-339. 
[Ciavarella 1999] M. Ciavarella, "Indentation by nominally flat or conical indenters with rounded corners", Int. J. Solids Struct. 36:27 (1999), 4149-4181.

[Ciavarella and Hills 1999] M. Ciavarella and D. A. Hills, "The influence of the indenter tip-radius on indentation testing of brittle materials", J. Eur. Ceram. Soc. 19:2 (1999), 239-245.

[Cundall and Hart 1992] P. A. Cundall and R. D. Hart, "Numerical modeling of discontinua", Eng. Computation. 9:2 (1992), 101-113.

[Elaguine et al. 2006] D. Elaguine, M.-A. Brudieu, and B. Storåkers, "Hertzian fracture at unloading", J. Mech. Phys. Solids 54:11 (2006), 2453-2473.

[Fu 2006] G. H. Fu, "Effects of tip rounding on the fundamental relations used in the analysis of nanoindentation data", Mater. Lett. 60:29-30 (2006), 3855-3856.

[Fu and Cao 2009] G. H. Fu and T. S. Cao, "On the fundamental relation used in nanoindentation with piecewisely defined indenters”, Mater. Sci. Eng. A 513-514 (2009), 276-278.

[Harsono et al. 2011] E. Harsono, S. Swaddiwudhipong, Z. S. Liu, and L. Shen, "Numerical and experimental indentation tests considering size effects", Int. J. Solids Struct. 48:6 (2011), 972-978.

[Hertz 1882] H. Hertz, “Ueber die Berührung fester elastischer Körper”, J. Reine Angew. Math. 92 (1882), 156-171.

[Heyliger and McMeeking 2001] P. R. Heyliger and R. M. McMeeking, "Cold plastic compaction of powders by a network model", J. Mech. Phys. Solids 49:9 (2001), 2031-2054.

[Hill and Storåkers 1990] R. Hill and B. Storåkers, "A concise treatment of axisymmetric indentation in elasticity", pp. 199210 in Elasticity: mathematical methods and applications, edited by G. Eason and R. W. Ogden, Ellis Horwood, Chichester, 1990.

[Hill et al. 1989] R. Hill, B. Storåkers, and A. B. Zdunek, "A theoretical study of the Brinell hardness test", Proc. R. Soc. Lond. A 423:1865 (1989), 301-330.

[Hills and Dini 2006] D. A. Hills and D. Dini, "A new method for the quantification of nucleation of fretting fatigue cracks using asymptotic contact solutions", Tribol. Int. 39:10 (2006), 1114-1122.

[Hills and Sackfield 1987] D. A. Hills and A. Sackfield, "The stress field induced by normal contact between dissimilar spheres", J. Appl. Mech. (ASME) 54:1 (1987), 8-14.

[Hills et al. 1993] D. A. Hills, D. Nowell, and A. Sackfield, Mechanics of elastic contacts, Butterworth-Heinemann, Oxford, 1993.

[Huang et al. 2006] Y. Huang, F. Zhang, K. C. Hwang, W. D. Nix, G. M. Pharr, and G. Feng, "A model of size effects in nano-indentation", J. Mech. Phys. Solids 54:8 (2006), 1668-1686.

[Jaffar 2002] M. J. Jaffar, "Frictionless contact between an elastic layer on a rigid base and a circular flat-ended punch with rounded edge or a conical punch with rounded tip", Int. J. Mech. Sci. 44:3 (2002), 545-560.

[Jelagin and Larsson 2008a] D. Jelagin and P.-L. Larsson, "On indentation and initiation of fracture in glass", Int. J. Solids Struct. 45:10 (2008), 2993-3008.

[Jelagin and Larsson 2008b] D. Jelagin and P.-L. Larsson, "Hertzian fracture at finite friction: a parametric study", Wear 265:5-6 (2008), 840-848.

[Johnson 1985] K. L. Johnson, Contact mechanics, Cambridge University Press, Cambridge, 1985.

[Larsson and Storåkers 2002] J. Larsson and B. Storåkers, "On oblique contact of creeping solids", J. Mech. Phys. Solids 50:10 (2002), 2029-2055.

[Lim and Chaudhri 2003] Y. Y. Lim and M. M. Chaudhri, "Experimental investigations of the normal loading of elastic spherical and conical indenters on to elastic flats", Philos. Mag. 83:30 (2003), 3427-3462.

[Martin and Bouvard 2003] C. L. Martin and D. Bouvard, "Study of the cold compaction of composite powders by the discrete element method", Acta Mater. 51:2 (2003), 373-386.

[Martin et al. 2003] C. L. Martin, D. Bouvard, and S. Shima, "Study of particle rearrangement during powder compaction by the discrete element method", J. Mech. Phys. Solids 51:4 (2003), 667-693. 
[Matsuoka and Yamamoto 1993] H. Matsuoka and S. Yamamoto, "A microscopic study on shear mechanism of granular materials by DEM and experiments", pp. 155-160 in Powders and grains 93 (Birmingham, 1993), edited by C. Thornton, Balkema, Rotterdam, 1993.

[Mossakovskii 1963] V. I. Mossakovskii, "Compression of elastic bodies under conditions of adhesion (axisymmetric case)", Prikl. Mat. Mekh. 27:3 (1963), 418-427. In Russian; translated in J. Appl. Math. Mech. 27:3 (1963), 630-643.

[Nowell et al. 2006] D. Nowell, D. Dini, and D. A. Hills, "Recent developments in the understanding of fretting fatigue", Eng. Fract. Mech. 73:2 (2006), 207-222.

[Pau et al. 2006] M. Pau, B. Leban, and A. Baldi, "Experimental analysis of contact for the indentation of a flat rounded punch", Int. J. Solids Struct. 43:25-26 (2006), 7959-7965.

[Rodriguez et al. 2011] S. A. Rodriguez, J. Alcala, and R. M. Souza, "Effects of elastic indenter deformation on spherical instrumented indentation tests: the reduced elastic modulus", Philos. Mag. 91:7-9 (2011), 1370-1386.

[Skrinjar and Larsson 2004] O. Skrinjar and P.-L. Larsson, "On discrete element modelling of compaction of powders with size ratio", Comput. Mater. Sci. 31:1-2 (2004), 131-146.

[Sneddon 1965] I. Sneddon, "The relation between load and penetration in the axisymmetric Boussinesq problem for a punch of arbitrary profile.", Int. J. Eng. Sci. 3 (1965), 47-57.

[Spence 1968] D. A. Spence, "Self similar solutions to adhesive contact problems with incremental loading", Proc. R. Soc. Lond. A 305:1480 (1968), 55-80.

[Spence 1975a] D. A. Spence, “The Hertz contact problem with finite friction”, J. Elasticity 5:3-4 (1975), 297-319.

[Spence 1975b] D. A. Spence, "Similarity considerations for contact between dissimilar elastic bodies", pp. 67-76 in The mechanics of the contact between deformable bodies: proceedings of the IUTAM Symposium on Mechanics of Contact (Enschede, 1974), edited by A. D. de Pater and J. J. Kalker, Delft University Press, Delft, 1975.

[Storåkers and Elaguine 2005] B. Storåkers and D. Elaguine, "Hertz contact at finite friction and arbitrary profiles", J. Mech. Phys. Solids 53:6 (2005), 1422-1447.

[Storåkers and Larsson 1994] B. Storåkers and P.-L. Larsson, "On Brinell and Boussinesq indentation of creeping solids", J. Mech. Phys. Solids 42:2 (1994), 307-332.

[Storåkers et al. 1997] B. Storåkers, S. Biwa, and P.-L. Larsson, "Similarity analysis of inelastic contact", Int. J. Solids Struct. 34:24 (1997), 3061-3083.

[Thornton and Antony 1998] C. Thornton and S. J. Antony, "Quasi-static deformation of particulate media", Phil. Trans. R. Soc. A 356:1747 (1998), 2763-2782.

[Thornton and Lanier 1997] C. Thornton and J. Lanier, "Uniaxial compression of granular media: numerical simulations and physical experiment”, pp. 223-226 in Powders and grains 97 (Durham, NC, 1997), edited by R. P. Behringer and J. T. Jenkins, Balkema, Rotterdam, 1997.

Received 24 May 2011. Revised 4 Jan 2012. Accepted 9 Jan 2012.

Denis Jelagin: denis.jelagin@abe.kth.se

Division of Highway and Railway Engineering, Royal Institute of Technology, SE-10044, Stockholm, Sweden

Per-LenNart LARSSON: pelle@hallf.kth.se

Department of Solid Mechanics, Royal Institute of Technology, SE-10044, Stockholm, Sweden 


\title{
JOURNAL OF MECHANICS OF MATERIALS AND STRUCTURES
}

\author{
jomms.net
}

\author{
Founded by Charles R. Steele and Marie-Louise Steele \\ EDITORS \\ Charles R. STEele \\ DAVIDE BIGONI \\ Stanford University, USA \\ University of Trento, Italy \\ IWONA JASIUK University of Illinois at Urbana-Champaign, USA \\ YASUHIDE SHINDO Tohoku University, Japan
}

\section{EDITORIAL BOARD}

H. D. Bui École Polytechnique, France

J. P. CARTER University of Sydney, Australia

R. M. CHRISTENSEN Stanford University, USA

G. M. L. GLadWELL University of Waterloo, Canada

D. H. Hodges Georgia Institute of Technology, USA

J. HUTCHINSON Harvard University, USA

C. HwU National Cheng Kung University, Taiwan

B. L. KARIHALOO University of Wales, UK

Y. Y. KIM Seoul National University, Republic of Korea

Z. Mroz Academy of Science, Poland

D. PAmplona Universidade Católica do Rio de Janeiro, Brazil

M. B. RUBIN Technion, Haifa, Israel

A. N. SHUPIKOV Ukrainian Academy of Sciences, Ukraine

T. TARNAI University Budapest, Hungary

F. Y. M. WAN University of California, Irvine, USA

P. WRIGGERS Universität Hannover, Germany

W. YANG Tsinghua University, China

F. ZIEGLER Technische Universität Wien, Austria

PRODUCTIONｃontact@msp.org

Silvio LEVY Scientific Editor

See http://jomms.net for submission guidelines.

JoMMS (ISSN 1559-3959) is published in 10 issues a year. The subscription price for 2012 is US $\$ 555 /$ year for the electronic version, and \$735/year (+\$60 shipping outside the US) for print and electronic. Subscriptions, requests for back issues, and changes of address should be sent to Mathematical Sciences Publishers, Department of Mathematics, University of California, Berkeley, CA 94720-3840.

JoMMS peer-review and production is managed by EditFLOw ${ }^{\circledR}$ from Mathematical Sciences Publishers.

\author{
mathematical sciences publishers \\ http://msp.org/ \\ A NON-PROFIT CORPORATION \\ Typeset in $\mathrm{IAT}_{\mathrm{E}} \mathrm{X}$ \\ Copyright $@ 2012$ by Mathematical Sciences Publishers
}




\title{
Journal of Mechanics of Materials and Structures
}

\author{
Volume 7, No.2 February 2012
}

Micromechanical analysis of unidirectional composites using a least-squares-based differential quadrature element method

Mohammad Bayat and Mohammad Mohammadi Aghdam

Size-dependent free vibration analysis of infinite nanotubes using elasticity theory

JAFAR ESKandari JaM, YASER Mirzaei, Behnam GHeShlaghi

and ReZa AvaZmohammadi

Spectral element model for the vibration of a spinning Timoshenko shaft

USIK LEE and INJOON JANG

On indenter boundary effects at elastic contact

Denis Jelagin and Per-Lennart LaRsson 165

Reflection of $P$ and $S V$ waves from the free surface of a two-temperature thermoelastic solid half-space

BALJEET SingH and KirAN BALA

A nonlinear Timoshenko beam formulation based on strain gradient theory ReZa Ansari, RAHEb GHOLAmi and MOHAMMAD ALI DARABi

Finite element analysis of bending-stiff composite conical shells with multiple delamination 